\title{
Mobilizing and strengthening knowledge for sustainable development in India
}

\author{
Mandakini Pant
}

University-community partnerships are based on the understanding that: (a) academics/researchers, practitioners (CSOs) and community members share a commonality of purpose for effecting sustainable development by producing knowledge to be used for the practical purpose of policy change and developmental interventions, contributing to theoretical elaboration and empowering communities through knowledge dissemination; and (b) they can be complementary to each other in achieving these goals. Each partner equitably contributes their expertise and shares responsibility and ownership to enhance understanding, integrate the knowledge gained, with action to improve the well-being of community members and foster sustainable development.

\section{Building linkages between research and community development}

\section{Context}

This study was a collaboration between Mountain Development Research Centre (MDRC) of Hemwati Nandan Bahuguna Garhwal University (HNBGU), Srinagar, Uttarakhand; Himalayan Action Research Centre (HARC); and Participatory Research in Asia (PRIA).

HNBGU was established in 1973, and upgraded as a central university in 2009. It has two teaching campuses, at Pauri and Tehri Garhwal. It is a residential-cumaffiliating institution of higher learning with more than 180 affiliated colleges covering seven districts of the region. It is considered to be among the top ten large universities in India.

\section{Objectives}

There was a felt need to bring to the table the problems specific to the Himalayan region. The objective was to use the university as a platform to raise these issues. The MDRC was established in 2005 within the university with these objectives:

- relating university research to respective state government departments;

- making students aware of rural development issues;

- training anthropology students on micro planning in collaboration with HARC. 
PRIA's academic linkage programme aimed to involve HEIs in communitybased research relevant to developmental goals and contributing towards public good. To this purpose it worked to create a common platform where research activities contributed towards community service, and created a linkage between the community and policymakers. This facilitated the collaboration between MDRC, PRIA and HARC.

Assistance from CSOs (PRIA and HARC) was primarily at the take-off stage in liaising with government departments and conducting orientations of university students, scholars and faculty on governance issues and participatory research. PRIA's expertise in the participatory research tool was extended to the university. HARC, having worked in the community for years, envisioned a new direction for the university, i.e., to contribute to community development.

With time, MDRC's domain of work has expanded and new methods were adopted to make its work more effective. MDRC now also works directly on community issues and is trying to ensure that existing rights are given to the people.

\section{Activities}

MDRC used the following approaches in its work:

- trainings and workshops;

- sharing information with government - postgraduate students were encouraged to undertake research projects on community development. When a research project was completed, it was shared with the community gram pradhan (village head) and governmental department heads. This ensured that local administration remained informed and took an active interest in initiating and completing relevant local developmental activities;

- public hearings - MDRC organized an interface between affected people and government. It negotiated and pushed government departments to answer people's queries. This was done in multiple rounds;

- linkage between academic research and community needs - a needs-based approach was followed to decide M.Phil. and Ph.D. research topics for university students, through the involvement of MDRC. Small organizations which work in the community were invited to the university to share their experiences and learning in the classrooms. This sensitized students and created a knowledge pool.

\section{Challenges}

The biggest challenge was financial. Given that small university projects receive limited sums for each project from the UGC, these projects were left to operate on their own.

The second challenge was political. With Garhwal University becoming a central university in 2009, the funding and permission for expansion of staff at MDRC had been put on hold, as the university was in a process of transition. 


\section{Outcomes}

- PRIA provided its expertise in participatory knowledge methods to the university - this was extremely important as this tool was employed to involve the community in knowledge generation, and efforts were made to unearth already existing traditional wisdom. Through this method, individuals who possess or have developed traditional methods to preserve nature and community have also come forward.

- The sound commitment of the university committee and each of its members - these people reflect a genuine concern for the people and the regions' socio-economic issues.

- Media provided good coverage to MDRC programmes.

- Goodwill that MDRC had earned for its honest and sustained efforts in furthering development of the region and people.

- Professional work culture of the two partner NGOs and their academic mindset which helped them to understand the nature of the centre's work.

\section{B Rural library services, Rural Extension Centre, Sriniketan}

\section{Context}

For Rabindranath Tagore, education was an essential component in human life. He also understood the importance of retention of acquired knowledge and literacy. As rural areas in India lacked basic amenities, Tagore developed and initiated the concept of mobile library services for rural communities with the inception of the Sriniketan Experiment in 1922.

\section{Objectives}

Tagore envisioned Sriniketan as a centre for rural reconstruction where integrated rural welfare programmes would be undertaken for solutions to problems in agriculture, industry, health, education and recreation, with a focus on reconstruction of the socio-economic life of villages, worked out by villagers themselves. His idea was to develop human resources, make use of available resources and develop sustainable rural organizations on cooperative principles.

\section{Activities}

Rural reconstruction programmes in Sriniketan were primarily organized and coordinated by the Rural Extension Centre (REC). REC is not an academic unit. Its programmes included:

- developing and strengthening Village Development Societies (VDS);

- extension education through adult and continuing education and community learning centres (CLCc);

- youth welfare work;

- health extension;

- women's development through women's groups;

- rural and mobile library services;

- cultural programmes in villages. 
This case study focused on the Rural Library Services intervention of REC. The objective of a rural circulating library was to retain acquired literacy skills after education. Tagore realized that children fell back into illiteracy after a short school education, because they had no access to books. The early initiatives did not have a specific blueprint or plan of action. Experience was gained through repeated experimenting with the methods and modes of community interaction. In 1975, with a matching recurring grant from the Raja Ram Mohan Roy Library Foundation (RRRLF) under the Ministry of Culture, government of India, library services became more structured and formalized. With grant-in-aid under the non-matching scheme of financial assistance to public library services, women, children, neo-literate, senior citizen and computer corners have also been established.

REC operated thirty-four rural libraries; books were contributed jointly by Vishva-Bharati Library Service and RRRLF. Village communities also mobilize books. These libraries were conceived not just for lending books and periodicals; they were also designed to address the needs for information, literacy, awareness and recreation of village communities.

The rural library was a participatory programme. Volunteers from the community functioned as librarians and assistant librarians. They received an honorarium of Rs.100 per month. REC organized a monthly seminar for the librarians, as a platform for discussion of problems and prospects about the functioning of libraries. Most of the librarians and assistant librarians were young. Participation of women, however, was small.

\section{Outcomes}

The programme aimed to achieve the following outcomes:

- development of knowledge power through dissemination of information;

- promotion and retention of acquired literacy skills;

- development of reading habits among rural people;

- enrichment of indigenous culture and tradition;

- sharing ideas and views with others on a common platform ;

- development of logical thinking and attitude of the villagers.

\section{Nature of partnerships}

Sriniketan's strategy for its rural reconstruction interventions had been to work with Village Development Societies (VDS). A VDS is a registered communitybased youth organization. The executive members of VDS comprised cultivators, students and schoolteachers. Again, though, participation of women was limited.

VDS were selected based on the credibility of the organization in the area and its experience and commitment towards rural welfare. After identification of prospective VDS, REC empowered them as vehicles of rural development by investing in streamlining organizational structure and functioning. It organized a number of formal training programmes to organize the VDS and finally affiliate them with REC's programmes. After affiliation, a VDS became the focal point of all interventions of REC in the village and for feedback to REC. The objective was 
to make REC programmes truly people-oriented and participatory.

VDS had funds to sustain themselves. Most VDS have developed a variety of indigenous resource mobilization strategies, such as guarding crops and ponds, share-grazing of cattle and processing of yields from agricultural land. Village members contributed voluntarily. They were also linked to other NGOs.

The VDS implemented all REC programmes, including the rural library services programme. VDS supported the envisioned roles and functions of rural libraries by:

- publishing an annual magazine, Shristi, comprising collected writings from readers;

- organizing demonstrations of the wall magazines of rural libraries on Library Day;

- organizing workshops for volunteers and meetings in villages with the readers to share and discuss issues, and collect requests for books.

A combination of methods was adopted for wider outreach, such as grass-rootslevel seminars; performing arts (folk and cultural programmes) by the readers; dialogue with schoolteachers, parents and readers; wall magazines and newsletters.

\section{Impact}

By providing universal access to library resources, services, materials and programmes, rural libraries inform, enrich, educate and empower a diverse community. Adult learners particularly benefited immensely from this programme.

The libraries have been extremely helpful for both school and college students, as they need not buy books. They also used computers in the library.

As information centres, rural libraries give villagers updated information. And seminars, workshops and cultural events provide villagers with a forum to communicate and interact in the pursuit of knowledge and ideas.

\section{Contributing factors for success}

- Tagore's vision has been the driving force;

- partnership and collaboration - the community-university partnership was built on community assets and supported creative solutions to local challenges. REC and VDS worked collaboratively to foster cross-sector partnerships to influence resources and build capacity in the target community.

\section{Emerging lessons from the case studies}

Community-university partnerships can serve as an entry point where local community-based organizations, village communities and public (government) agencies work together in the area of community development and educational enrichment. The cases of MDRC and REC's rural library services clearly show that partnership with community members and CSOs has a unique potential for valuing indigenous knowledge, action research participation and knowledge production around citizens' concerns. 
The MDRC case in particular reveals the ways new knowledge, concepts, insights and practical innovations in knowledge building can foster social transformation. Universities can nurture active citizenship by addressing an array of critical challenges confronting marginalized communities, contributing to their social and economic well-being. Students become sensitized to the challenges of social justice and a deepening of democracy in the context in which they live. Through their research, they learn to respect people's knowledge, otherwise not valued.

The case of rural library services highlights the ways adult, continuing education and extension centres within universities can transform the university system into an active instrument for social change. Information, knowledge and corresponding knowledge productions are the key resources of power in much the same way as is capital.

\section{Challenges to community-university partnerships}

- Building a consortium/network between community, practitioners, academia, policy institutions, government departments, NGOs and corporate sectors for the use of the knowledge generated. An international network would be particularly valuable where there is experimentation on CBR in universities throughout the world.

- Using systematic documentation and synthesis of the lessons from the partnership for promotion of appropriate public policies and programmes.

- Fostering a culture of knowledge sharing among community members. Local knowledge is a vital resource for cultural promotion, learning and literacy.

- The community-university initiatives in rural libraries have used a traditional approach to library management, which does not necessarily reflect the needs of all members of the community.

- Innovative courses and curricula to respond to and stimulate students to accept responsibility for and to meet societal challenges.

- Theoretically valid generation of knowledge by universities through research and services.

- Multidisciplinary support from the university from the vantage point of community.

- Funding of community-university partnerships to reinforce existing programmes for community empowerment and to support efforts to become more multidimensional.

- Creating a critical mass of library and information workers with skills and commitment to offer innovative services to poor and marginalized communities and to create strong literate environments.

- Role of libraries as information centres must include clear strategies to deliver information in appropriate formats, languages and subject matter.

- Need for mixed-and-matched-ICT (information and communication technology) and other communication technologies to achieve the best results for different contexts. 